\title{
Correction to "Pharmacological Activation of Thermo-Transient Receptor Potential Vanilloid 3 Channels Inhibits Hair Growth by Inducing Cell Death of Hair Follicle Outer Root Sheath"
}

\begin{abstract}
The above article [Yan K, Sun X, Wang Y, Liu Y, and Wang KW (2019) J Pharmacol Exp Ther 370(2): 299-307; DOI: https://doi.org/10.1124/jpet.119.258087] was miscategorized as Behavioral Pharmacology. The article would be more appropriately categorized in Cellular and Molecular. The HTML and PDF versions of the article and August 2019 Table of Contents have been corrected.
\end{abstract}

The authors apologize for any inconvenience caused by this error. 